\title{
Information and drugs at our fingertips
}

\author{
Sophie Cook clinical editor
}

The BMJ

International groups of patients are linking up 24/7 through social media to disseminate knowledge, provide peer support, and offer clinical advice. And all of this is delivered quickly, at the touch of a button.

Evolution of patient groups from infrequent local meetings in person to virtual international networks is surely a good thing? Stephen Armstrong explores the role of social media in patient support (doi:10.1136/bmj.i4201) and considers the benefits, ethical dilemmas, and confidentiality issues that arise. Maureen Baker, chair of the Royal College of General Practitioners, acknowledges the huge benefit of such groups but cautions that "these forums should not be seen as a replacement for proper medical care."

The messages from patients, however, seem to be of hope and relief at the opportunity to share and connect across a wider expert group. In a BMJ Blog Matthias Wienold talks about his involvement with the Cluster Headache Support Group and describes how a Facebook group with more than 8000 members contributes to research and enables patient engagement and conferences (http://blogs.bmj.com/bmj/2016/06/15/how-anonline-patient-group-proved-its-value-to-me). This is a testament to the benefit these forums offer beyond provision of support to individuals.

Although social media have revolutionised access to information, concern remains over delay in access to new treatments created by existing models of drug development.
Courtney Davis and colleagues (doi:10.1136/bmj.i4437) scrutinise the European Medicines Agency's new “adaptive pathways" approach to drug testing and marketing, a model designed to accelerate the delivery of new drugs that answer "unmet medical needs." But the approach relies on preliminary clinical data, surrogate outcomes, and observational studies, which may "risk reaching incorrect conclusions about the benefit-harm balance of new drugs," they say. The German Institute for Quality and Efficiency in Health Care (IQWiG) is also concerned and has called for the scheme to be paused (doi:10.1136/bmj.i4479).

Striking the right balance to satisfy everyone is a challenge, and although quicker access to new drugs is desirable, questions about safety remain to be answered.

Finally, what's in a name? "Junior" doctor Michael Moran, who has a masters degree, a $\mathrm{PhD}$, and 11 years of clinical experience, asks whether it's time to update this ambiguous title (bmj.co/ definejunior). Also on BMJ Blogs The BMJ's patient editor, Rosamund Snow, explains that if she has to judge someone on seniority it is more likely to be based on their confidence and authority "than the colour of their scrubs or the latest medical acronym" (bmj.co/juniorpatient).

The jury is out on an appropriate alternative title (bmj.co/ lavellejones; doi:10.1136/bmj.i4496) Why not respond to these articles with your suggestions? 